\title{
THE NOVEMBER MEETING IN LA JOLLA
}

The six hundred ninety-eighth meeting of the American Mathematical Society was held at the University of California, San Diego, in La Jolla, California, on Saturday, November 18, 1972. There were 110 registrants at the meeting, including 89 members of the Society.

By invitation of the Committee to Select Hour Speakers for Far Western Sectional Meetings, there were two invited hour addresses at this meeting. Professor Marc A. Rieffel of the University of California, Berkeley lectured on Induced representations and Morita equivalence for $C^{*}$-algebras. Professor Jacob Korevaar introduced Professor Rieffel. Professor Ichiro Satake of the University of California, Berkeley presented the second hour address. The title of his talk was On the arithmetic of tube domains. He was introduced by Professor Errett Bishop.

There were five sessions of contributed ten-minute papers, chaired by Professors David Adams, Allen Altman, Donald W. Anderson, Burton Rodin and Takayuki Tamura.

HoNOlulu, Hawail

R. S. PIERCE Acting Associate Secretary 